\title{
THE TOURISM EDUCATION FUTURES INSTITUTE (TEFI): ACTIVATING CHANGE IN TOURISM EDUCATION
}

\author{
Pauline J. Sheldon \\ University of Hawaii, USA \\ psheldon@hawaii.edu \\ Daniel R. Fesenmaier \\ Temple University, USA \\ drfez@temple.edu \\ and \\ John Tribe \\ University of Surrey, UK \\ j.tribe@surrey.ac.uk
}

Corresponding Author: Pauline Sheldon, School of Travel Industry Management, University of Hawaii, 2560 Campus Road, Honolulu Hawaii 96822, USA. Email: psheldon@ @awaii.edu, Phone 8089568078. 


\title{
The Tourism Education Futures Institute (TEFI): Activating Change in Tourism Education
}

\begin{abstract}
The Tourism Education Futures Institute (TEFI) seeks to provide vision, knowledge and a framework for tourism education programs that promote global citizenship and optimism for a better world. This paper provides background on TEFI, its inception, its development and its future. The paper argues that a fundamental shift in tourism education is necessary to respond to global challenges impacting tourism at a fundamental level. These shifts demand higher levels of responsibility and stewardship by graduates and industry leaders. TEFI attempts to address the complexity and diversity of the shifts required by educational institutions and industry. TEFI's work began by defining a set of foundational values for tourism education programs worldwide (stewardship, ethics, knowledge, mutuality, professionalism). TEFI is also addressing other important shifts needed to provide an education of quality and relevance to tomorrow's tourism industry.
\end{abstract}

Keywords: Tourism education, futures, values, responsibility, stewardship, ethics 


\section{The Tourism Education Futures Initiative (TEFI): Activating Change in Tourism Education}

\section{$1 \quad$ Introduction}

Tourism is a hallmark activity of the postmodern world. As such, it is a significant factor in world-making and people-making. The same can be said for universities - they are major enterprises and, historically, have been important sources of innovative thinking and change. The intersection of tourism and universities is, therefore, a powerful nexus of potential influence. From an industry perspective, tourism employment in the coming decades must have a very different profile than it does today. In 2020, students will be applying for jobs that do not even exist today, and much of what we teach our students is obsolete by the time they graduate. Students entering the uncertain world of the future and in particular, the vulnerable tourism sector, need different skills, aptitudes and knowledge to succeed. To meet the challenges of the next few decades, tourism educational systems, however, are in need of radical change. Indeed, Wallis and Steptoe (2006) and many others argue that a fundamental re-tool and re-design is necessary; not incremental change, but change in the nature of what is taught and how it is taught. Further, skills and knowledge sets must be redefined, structures and assumptions need to be questioned; thus, the "old ways of doing things" must be transcended.

The challenges facing the tourism industry and tourism educators call out for a new paradigm of tourism education. In an attempt to address these challenges, the Tourism Education Futures Institute (TEFI) was born by a few concerned tourism educators (Sheldon et al, 2008). The purpose of this paper is to outline a framework developed by TEFI for the future development of tourism education. Its content is based on the input of about 80 experienced educators and industry leaders who met four times between 2007 an 2010 to discuss and debate 
the need for change and to provide recommendations for a framework for a new tourism curriculum for 2015-2030. Specifically TEFI has the following mission: TEFI seeks to provide vision, knowledge and a framework for tourism education programs to promote global citizenship and optimism for a better world. The vision of TEFI is to not only work to reshape tourism education worldwide, but to help the leaders of the tourism industry follow practices that are rooted in basic values.

The TEFI was born in 2007 when a few tourism educators and industry met in Vienna, Austria to discuss the status of tourism education. During this meeting, a process emerged that provides a framework for the development of TEFI. Subsequent meetings in Hawaii, USA, Lugano, Switzerland, and San Sebastian, Spain built on the work in Vienna. TEFI is organized around a process which is both proactive and action oriented, focusing on translating the core values articulated by the participants into implementation to bring about fundamental change in tourism education.

An important initial outcome of the TEFI process is a set of five values-based principles that tourism students should embody upon graduation to become responsible leaders and stewards for the destinations (including hospitality and other tourism related businesses and organizations) where they work or live. The five value sets are: Ethics, Stewardship, Knowledge, Professionalism and Mutuality, and are discussed in more detail later in this paper. They are portrayed as interlocking values because of their interconnectedness and their permeability. This paper provides more detail on these value sets, how they can be incorporated into the learning experience for tourism students, and examples of courses incorporating these values.

Another dimension of the TEFI process is the Working Groups that develop a range of 
tools for educating tourism students. These Working Groups are now involved in a number of activities including: a faculty and student Code of Ethics; an outreach pilot program to universities worldwide; and a 'values inventory' to be used as part of program assessment. Working Groups are currently finalizing their tools and outcomes. The next TEFI meeting will be the TEFI World Congress: Activating Change in Tourism Education at Temple University Philadelphia, USA May 18-21, 2011. Educators and industry leaders from around the world are invited to attend.

\section{Background and Rationale}

The intersection of the tourism industry and universities is a powerful nexus for tourism education in that both universities and tourism are products of the world - hence, a paradox exists in that they are both shaped by the world and have the potential to shape it. This paradox presents a challenge for tourism educators. Being part of the world, and not distant or removed from it, is of course important so that academics do not retreat to ineffectual ivory towers. That is to say, they should offer participation as well as critique and therefore universities should not just become places of critique. They should contribute to a productive world by developing a highly skilled workforce. But being shaped by the world also means that tourism education faces a number of challenges.

The first of these challenges is avoidance of unthinking reproduction (Apple, 1990). Here, the existing world model and machine, buttressed with solid structures and deeply impregnated by ideology (Althusser, 1984) has an innate tendency to reproduce itself in its current form. If caught in this simple, yet possibly blind cycle of reproduction, students learn to fit in passively to the world that exists (Minogue, 1973) rather than to create challenging vistas. 
Related to this is a second tendency to concentrate on means rather than ends. That is to say, our present configuration of the tourism world tends to create a number of immediate problems that need solving (for example in marketing, operations, service quality and logistics). Universities are called upon to produce human resources that can solve these problems. The urgency of the day to day inevitably competes for space with the equally urgent, but never quite so pressing issues of the future. Here, we can allow the vocational to supplant the philosophical (Tribe, 2002), giving insufficient attention to questions of desirable ends and the kind of tourism world we wish to create.

The late 1980s saw the crisis of communism marked by the symbolic fall of the Berlin Wall. The year 2008 saw the crystallization of a third significant challenge - the crisis of capitalism marked by the symbolic fall of major banks including Lehman Brothers. This has surfaced the challenge of appropriate corporate and broader societal values. Here, university business schools have been fiercely criticized for a failure to give adequate attention or leadership to this part of the curriculum for future business leaders.

The fourth challenge relates to sustainability and is neatly captured by Giddens' Paradox (Giddens, 2009). This is the paradox of climate change where Giddens notes that since we are not currently unduly affected by the outcomes of climate change we fail to act. But when we are finally pressed into action by its consequences it will be too late to do anything about them.

The fifth challenge is that tourism might be read as another product of some form of Washington Consensus (Williamson, 1997). For example, its terms of trade (between supplier and consumer), its rules of engagement, its allowed and disallowed moves, its tolerance of inequality, indeed its general configuration performs to generate a predictable structure of winners and losers legitimized by a script of neoliberalist values. 
A sixth and final challenge is that of extent and pace of change. Patterns of consumption, technological change and supply innovation in tourism as elsewhere are in a constant state of transformation. This mean that graduates may find that their degrees only offer a few years of currency rather than a lifetime of expertise (Cooper et al., 2007). This clearly stresses the need to understand and promote lifelong learning to underpin professional expertise.

These challenges set the context for TEFI. A central task is to educate tourism graduates (e.g. undergraduate and graduate students) to satisfy the demands of the market place as productive employees for a fast changing world. The tourism industry expects its workforce to be well trained, and society might expect a contribution from universities in terms of enhanced economic performance. But any deep consideration of the term society generates other inescapable questions about what kind of tourism is to be developed. Here, it is argued that we need to re-think and re-engineer our tourism courses and our students' experiences. Further, it is argued that we need ourselves and our graduates to lead the debate about a set of values that should govern the development of the tourism world. If we achieve this, we would be at the forefront of people-making and world-making through tourism.

\section{The TEFI Process}

As highlighted previously, the seeds of TEFI are based upon the general recognition that higher education and more particularly, tourism education, must change in order to meet the challenges that face tourism and society. Additionally, it was recognized that many people (e.g. academicians, teachers, industry professionals, and government leaders) throughout the world have expressed their concerns regarding the future. Led by these voices, a number of innovators concerned about the future of tourism education met in Vienna, Austria to discuss the status of 
tourism education and to assess the degree to which there was an agreement concerning the need to develop alternative models for tourism education. During this meeting, a process emerged that provides a framework for the growth and development of TEFI. That is, TEFI is largely organized around a process which is both proactive and action oriented, focusing on translating the core values it has articulated into action and implementation to create a fundamental change in tourism education. The TEFI process includes two important action settings: 1. An annual Summit, which brings together innovators from around the world to consider issues related to tourism education; and, 2. Working Groups, which throughout the year seek to develop tools that can be used to affect tourism education.

The Annual Summit has been comprised of 30 - 40 leading scholars and industry professionals and has included a series of lectures and breakout discussion groups. The lectures are conducted to stimulate thinking and to challenge the status quo. For example in the first Summit, Dr. Jim Dator, a leading futurist from the University of Hawaii, challenged the TEFI members to develop scenarios of future worlds, and then to propose possible solutions/responses to these scenarios. In the Second Summit, Dr. John Tribe (University of Surrey) articulated a vision of hope for the future of society and tourism education, in particular. But he also challenged the group to take personal responsibility in shaping this future world. Dr. Gianna Moscardo (James Cook University) focused on the learning styles of the next generation, arguing that how we teach is just as important as what we teach. And, Scott Meis, former director of research for the Tourism Industry Association of Canada, demonstrated quite conclusively that the industry need for qualified employees will become even more critical over the next decade. The Third Summit focused on barriers to change within the university (as discussed by Dr. Thomas Bieger of the University of St. Gallen) and strategies for programmatic change (as 
exemplified in lectures by Drs. Irena Ateljevic, Simon Wong, Loredana Padurean and Betsy Barber). These presentations clearly demonstrated barriers and potential strategies for changing educational processes within the university; they also highlighted a number of conflicts within higher education in realizing the changes. The Fourth Summit in San Sebastian, Spain focused on the status of the Working Groups and the various tasks they have considered over the year, and on preparation for the TEFI World Congress to be held at Temple University, Philadelphia, USA 18-21 May 2011.

While the "lectures" provide the starting point of discussion, the main work of TEFI is in the breakout groups that provide the setting for ideation, creativity, dialog and problem resolution. Throughout the TEFI Summits, the group members are tasked to develop position statements regarding the various issues related to the theme of the annual meeting. Then, the results of these efforts were presented to the entire TEFI body for clarification and ultimate approval.

The second pillar of the TEFI process is the Working Group. These Groups are tasked to move the TEFI agenda forward between Summits by providing essential energy and direction resulting in concrete action-oriented tools that can be used by TEFI. For example, prior to the first TEFI summit, a Working Group identified a core set of readings that established a foundation - a common language and set of ideas and ideals - for discussion. In addition, the Working Group conducted a pre-meeting survey of participants regarding key knowledge and skill sets needed for the tourism graduate of the future. Three different Working Groups emerged from the first Summit, focusing on defining a set of values to drive the TEFI agenda forward, identifying case studies in values-based education, and evaluating outcome-based education as a tool to assess programmatic changes. Each of the Working Groups developed working papers 
and presentations which are then presented and discussed at the next TEFI Summit.

And finally, as the result of the Third Summit, a series of Working Groups were identified to create concrete "tools" for supporting TEFI-based initiatives. These Working Groups included proposing a Faculty Code of Ethics, developing an outreach pilot program to universities worldwide, and developing a 'values inventory' which may be used as part of program assessment.

\subsection{TEFI Values}

The first TEFI Summit explored various futuristic scenarios of society that tourism education programs would need to adapt to. It was decided that attempting to modify tourism education programs to fit a multitude of possible world scenarios, or even a single preferred scenario was a task fraught with too much specificity and too much uncertainty. Instead, a consensus among TEFI participants concluded that whatever the world scenario in the future, certain values would provide the students with the foundation to meet the multitude of uncertainties of the future. Given this consensus, the work of TEFI moved to define these value sets.

The five values-based principles that TEFI identified to be embodied in tourism education programs so that students become responsible leaders and stewards for the destinations where they work or live are shown in Figure 1 (see below). Specifically the five values are: Ethics, Stewardship, Knowledge, Professionalism and Mutuality. They are conceptually portrayed as interlocking Value Principles demonstrating their interconnectedness and permeability. It is envisioned by TEFI members that educators can use subsets of the five value principles to integrate into their courses as appropriate. Each values-based principle is discussed 
below with an emphasis on how that concept can be incorporated into the tourism student learning process. For each principle we describe its definition, the content that should be included in the learning experience, and specific learning objectives.

Insert Figure 1 here

\subsection{Ethics}

\section{Definition}

Ethics is concerned with distinguishing between behavior that is right and behavior that is wrong. It is the basis for good action and provides a framework for judging actions that are questionable. Ethical behavior means striving for actions that are deemed "good" based on principles and values. It also involves making such principles and values explicit and rendering the processes that lead to decisions transparent. Recognizing that good actions do not occur in a vacuum but are derived from specific value systems further requires understanding and respect for actions based on different systems.

\section{Content}

Teaching ethics involves:

1. Introducing students to Ethics as a field of study with practical importance
a. Defining Ethics
b. Encouraging reflexivity and decolonization of the self
c. Recognizing diversity
d. Outlining the practical importance of ethical behavior
e. Discussing the specific issues and challenges in the context of tourism 
f. Exemplifying the implications of unethical behavior

g. Identifying the stakeholders in certain ethical dilemmas

2. Exposing students to different ethical traditions and principles

a. Helping students understand what traditions and principles exist (e.g.

Utilitarianism, Kantian ethic of respect for others, Aristotelian virtue ethics,

Religion, Principles of benevolence, honesty, autonomy, justice, etc.)

b. Explaining the evolution of these traditions

c. Illustrating how these traditions and principles influence actions

d. Highlighting differences and potential areas of conflict

3. Equipping students with the means to achieve reconciliation

a. Explaining how Ethics informs judgment

b. Engaging students in principles of negotiation

c. Illustrating ways in which conflicts can be resolved and compromises reached

4. Drawing connections to issues of power and politics

a. Identifying sources of power

b. Discussing the importance and principles of the legitimization of power

c. Emphasizing the role of existing power structures in determining ethical outcomes

5. Evoking actions

a. Exposing students to sources which can guide their actions

b. Encouraging students to develop their own Codes of Conduct

c. Having students identify and implement good actions 
Specific Student Learning Objectives in the Tourism Context

Students who study Ethics in the tourism context should be able to:

- recognize its importance in general and specifically for tourism,

- judge their own and others' actions,

- value transparency,

- respect different ethical traditions/approaches

- identify potential and actual conflicts and set actions in place to mitigate them

- know which resources are available when dealing with ethical concerns

- provide ethical leadership and initiate changes for the better

\subsection{Knowledge \\ Definition}

Knowledge can be described as: 1. expertise and skills acquired by a person through experience or education; 2. the theoretical or practical understanding of a subject, 3. facts and information about a field, or 4. awareness or familiarity gained by experience of a fact or situation. This implies that knowledge is more than data (summary descriptions of parts of the world around us) and more than information (data put into a context). Knowledge comes in both explicit and tacit formats. In most instances, it is not possible to have an exhaustive understanding of an information domain so knowledge is ceaselessly incomplete. Knowledge is created through processes of selecting, connecting and reflecting. Knowledge is always already predicated by existing knowledge, which means that knowledge involves interpretation and contextualization and existing knowledge should be challenged. 


\section{Content}

The knowledge creation process should address creativity, critical thinking, and networking for change and innovation through complex cognitive processes of perception, reasoning, learning, communication, association and application.

\section{Creativity}

Creativity has been identified as a key factor to adequately address the seismic changes facing contemporary society and as a driving force towards knowledge creation and socioeconomic advancements (European University Association 2007). It is often useful to explicitly distinguish between creativity and innovation. Creativity is typically used to refer to the act of producing new ideas, approaches or actions that are appropriate to the problem at hand, while innovation often begins with creative ideas and involves a process of both generating and applying such creative ideas in a specific context for a human, cultural or economic purposes. The ethical dimension of creativity and creative knowledge should be addressed. Dealing with future insecurity and uncertainty requires "thinking outside the box", looking at existing domains and problems from a new angle. Promoting such a culture of creativity that acknowledges and seeks to learn from failure encourages students to move from hypothesis and conventional knowledge towards possibilities and originality. Creativity and knowledge formation takes place in an organizational set-up, for example but not exclusively, in the format of educational institutions or business organizations. It is essential to envisage outcomes consisting of both factual and procedural knowledge, and that finding a balance between the two are essential for the comprehension and application of knowledge.

\section{Critical thinking}


Critical thinking calls for an unrelenting examination of any form of knowledge and the knowledge creation process to recognize the existence (or non-existence) of the use and power that supports it and the further conclusions to which it tends. It is important that knowledge is contextualized in order to recognize unstated assumptions and values. Critical thinking is not only about criticizing but being critical of the constitution of knowledge and underlying dogmas. Students should therefore be encouraged to make the implicit explicit and identify ethnocentric bias and prejudice whenever deciding upon or solving a problem. Embodying an ethical dimension in mainstream disciplines in social sciences can enrich the thinking and add relevant dimensions of critical thinking, not only for the critique as an academic exercise, but critique as part of a constructive pursuit. Responsible citizenship evolves through knowledge enhancing critical thinking.

\section{Networking}

The dissemination and development of knowledge take place in social environments. Social networks can create or assist in refining the use of knowledge. Bridging social networks can link different repositories of knowledge with the potential innovation effects. Networks and knowledge repositories are become more open as a consequence of the development of technical and institutional remedies connected to the social media. Hereby, problem solving and identification increasingly take place through sharing and cooperation in open knowledge systems, where providers and users of knowledge meet and exchange information. Students and higher institutions of education must understand and address the issues of open knowledge sources and open innovation, which are in contrast to issues of knowledge hoarding, protection and monopolizing in closed learning environments. New ways of thinking about the professions 
are essential. Higher educational institutions must prepare students to become practitioners, researchers, philosophical scholars and knowledge brokers throughout their studies and in their subsequent careers.

Specific Student Learning Objectives in the Tourism Context

As a phenomenon, industry, career and lifestyle tourism constitutes exceptional learning opportunities. The specific student learning objectives in the tourism context are:

- Understanding the value and power of knowledge rather than data or information

- The art and skill of sharing knowledge, including new codes of conduct

- Harvesting from new knowledge intermediaries

- Developing equitable ways of communication with industry and community - across national borders and disciplines

- Humility and courage in the fields of data creation and management, information management and knowledge creation and management

- The art of questioning the answer - challenge what is taken for granted

- Letting go - risking the adventure of creative journeys, using creativity tools and new ways of collaboration

- Strengthening students' critical thinking skills through interactive teaching processes

- Shifting from solely valuing and rewarding individual achievement toward collective action, participation and contribution. 


\subsection{Stewardship}

\section{Definition}

Implicit in stewardship is the notion of responsibility; responsibility towards the natural world and humanity. It implies the ability to care for something and the accountability to exercise that ability. In the tourism context this implies taking care of the earth and in particular its tourism destinations for the benefit of future generations. Tourism faculty and students should learn to take leadership in three distinct aspects of stewardship: sustainability, responsibility and service to the community.

\section{Content}

Stewardship requires managing resources and the impacts of tourism for future generations. Implicit in this concept is the idea that all human beings should have quality lives, including taking vacations, rather than just a few. The concept of sustainability also suggests the need to search for a state of equilibrium and a balancing of environmental, socio-cultural, and economic systems. This often implies restraining economic growth if such growth endangers social or environmental well-being. A continuing state of equilibrium will require constant intervention in the functioning of the system. In the context of tourism this may well mean an end to the use of tourist numbers and tourism revenues as key performance indicators.

Stewardship can only be achieved if individuals and organizations acknowledge their responsibilities and act accordingly. All stakeholders have responsibility for the environment and the society, requiring the use of influence or power. Responsibility also implies the existence of rights. If all stakeholders take responsibility for the future of the planet in tourism, empowerment of those who are currently powerless is necessary, as is the restraint of power of 
other groups. The stakeholders with responsibilities include destination governments, generating country governments, tourism industry firms and organizations, employees, tourists, host communities, media and investors.

Finally, stewardship includes service to the destination community, allowing stakeholders to take responsibility. In the context of tourism education, in addition to the destination host community other communities worthy of consideration: students, graduates, and the global tourism academic community. Volun-tourism is an example of implementing service to the destination community. Whilst the motives for this activity are undoubtedly good, there are questions as to whether this is an appropriate way of achieving a more sustainable world. Specific Student Learning Objectives in the Tourism Context

In order to implement knowledge of stewardship in the tourism curriculum we propose the following certain knowledge and skills be included. It will be critical that students are exposed to debates, many of which will be uncomfortable. Educators must also consider whether they have the right or the responsibility to inculcate particular values in students. Including stewardship into the tourism curriculum will require this self-reflection by the educators.

The specific learning objectives are:

1. Understand social and ecological systems

2. Be able to explain environmental governance and policies

3. Be able to apply adaptive management and adaptive co-management concepts

4. Understand tourists' ecological footprint

5. Understand the precautionary principle

6. Know environmental management systems

7. Understand the relationship between climate change and tourism 
8. Understand different kinds of sustainable business practices and operations

9. Know how destinations can be managed to become more sustainable

10. Critically evaluate the impact of their own vacations

11. Undertake tourism-related projects that serve a community

12. Understand the various motivators of stakeholders in the tourism system, and the various power structures between these stakeholders.

\subsection{Professionalism}

\section{Definition}

'Professionalism' is a rather nebulous term as it implies not only a profession and the skills, competencies or standards associated with it, but also an attitude and behavior that reflect these. It has also been defined as the ability to align personal and organizational conduct with ethical and professional standards that include a responsibility to the customer or guest and community, a service orientation, and a commitment to lifelong learning and improvement.

Professionalism is defined as incorporating leadership, a practical approach (practicality), attention to services, concern for the relevance and timeliness of evidence, reflexivity, teamwork and partnership building skills, and proactivity. Proactivity involves taking the initiative to address problems in one's service domain and a commitment to excellence in one's domain of expertise. According to Bateman and Crant (1993), “[p]roactive people scan for opportunities, show initiative, take action, and persevere until they reach closure by bringing about change. They are pathfinders (Levitt, 1988) who change their organization's mission or find and solve problems" (p. 105). This is inkeeping with leadership, which is the ability to inspire individual and organizational excellence, to create and attain a shared vision, and to 
successfully manage change to attain the organization's strategic ends and successful performance.

\section{Content}

The core values of professionalism are a requirement for all tourism and hospitality academic programs. It is educators' responsibility to expose students to high quality and appropriate professionalism. The term 'new professionalism' is used by Sachs (2003) to distinguish between 'old' forms of professionalism which debate characteristics of professions and the extent to which occupational groups might be acknowledged as professions, and 'new' forms which, claims Sachs, assume a 'changed analytical perspective' and are seen to be more 'positive, principled and postmodern' (p. 182). The distinction between old and new forms of professionalism is useful, although the notion that new forms of professionalism are necessarily 'positive' and 'principled' should be considered with caution, as there is also evidence of a less 'principled' discourse in action.

While there is no overall agreement as to what constitutes a profession, certain key aspects are commonly cited that seek claim to professional status. These generally include reference to specialist knowledge, autonomy and responsibility (Hoyle \& John, 1995). Professionalism, therefore, implies that such characteristics are evident in an individual's work. It is also linked to ethic or ethical behavior. Some refer to it as an emotion, or a feeling of being professional. TEFI appears to include some of both, where professionalism is a series of behaviors and beliefs. To achieve success in the behavior of professionalism requires an attitude (ethical belief) of what makes a true professional. It also seems that leadership is key; because the professional that exhibits the most positive leadership often displays the other components in a positive manner as well. 


\section{Specific Student Learning Objectives in the Tourism Context}

The two sections below identify the content to be transferred in the learning process. The way in which this can be done is discussed in general at the end of the two sections.

1. Relevance, Reflexivity, Timeliness

- Product innovation - often high risk, involving substantial investment in people, time and money - involves the introduction of a new good or service that is new or substantially improved. This might include improvements in functional characteristics, technical abilities, ease of use, or any other dimension.

- Product improvement - improving current systems and products, which may only require minimal investment, but can result in substantial profit increase.

- Process innovation - involves the implementation of a new or significantly improved production or delivery method.

- Process improvements - improvements in the way we do things. This usually involves no or little risk.

- Service innovation - refers to service product innovation which might be, compared to goods product innovation or process innovation, relatively less involving technological advance but more interactive and information-intensive. This type of innovation can be found both in manufacturing and service.

- Accreditation and certification: refers to the use of such schemes to introduce more professionalism into the tourism sector.

\section{Practicality, Partnership, Leadership}

- Business model innovation 
- Marketing innovation

- Supply chain innovation - where innovations occur in the sourcing of input products from suppliers and the delivery of output products to customers

- Substantial innovation - introducing a different product or service within the same line, such as the movement of a candle company into marketing the electric light globe

- Organizational innovation - involves the creation or alteration of business structures, practices, and models, and may therefore include process, marketing and business model innovation.

Using Bloom's Taxonomy to determine learning objectives with respect to professionalism, the first stage would be knowledge and comprehension of the concepts underpinning professionalism: list, define, describe, identify, show, label, collect, examine, summarize, describe, interpret, contrast, differentiate, and discuss. The second stage involves application and analysis: apply, demonstrate, calculate, illustrate, show, solve, examine, classify, experiment, discover, analyze, separate, order, explain, connect, compare, and select. The third stage includes synthesis and evaluation: combine, integrate, modify, plan, create, design, invent, compose, prepare, generalize, rewrite, assess, decide, grade, test, measure, recommend, convince, judge, explain, discriminate, support, conclude, and, summarize. The students could either be exposed to a case study or an actual experiential learning environment (e.g., internship) where the assessment criteria would be incorporated into the learning objectives and the assignments given. 


\subsection{Mutual Respect}

\section{Definition}

Within the TEFI framework mutual respect has been initially defined as diversity, inclusion, equity, humility, collaboration. However, during the TEFI III summit the meaning of this value was refined and extended by the participants. Mutual respect is seen as a value grounded in human relationships that requires attitudinal developments that are evolving, dynamic and involve acceptance, self-awareness of structural inequalities, open-mindedness, empowerment, and ability to revisit one' cultural understanding of the world.

\section{Content}

Several important elements of the mutuality value are highlighted:

1) Mutuality is a process that is evolving and dynamic, emphasising that achieving mutual respect is a long-term and even life-long learning process that can be developed at different levels, starting from the individual to the society and global levels. It also can apply to human-animal relationships particularly in the context of how animals are used in tourism. This development from survival values of one's own isolated existence to relational/global consciousness of mutuality has been researched for the last 25 years by eminent sociologist Ronald Inglehart (1990; 1997). In his longitudinal World Values Survey covering two-thirds of world population he has been capturing global evolution of the personal, social, public and cultural values which he conceptualises under a theory of a 'Spiral of Values' (see also Webster, 2001).

2) Mutuality starts with self-awareness and understanding of own identity, values, cultural drivers and behavioural patterns. Understanding self-identity is a prerequisite to 
understanding values and believes of other people, and developing positive attitudes to diverse identities. It is important to recognize that structural inequalities exist, including race, sex, gender, religion etc, and acknowledge these inequalities to eliminate the bias. Selfawareness also helps to question "I versus Them" attitude and move from comparing and contrasting to accepting and sharing. Self-awareness also helps to perceive self as a positive change agent.

3) Mutual respect is about behaviours and attitudes. Respect of self and others is an attitude which involves recognition and acknowledgement of other people's views. It goes beyond formal structures and legal frameworks for social inclusion and diversity, and it is grounded into early age education.

4) Mutuality is grounded in human relationships. Respect of self and others is developed through open interactions, through constructive communication and discussions, conflict avoidance and management, empathy and acceptance. Mutuality is about developing respectful relationships between self and people through sharing and understanding values and attitudes. Mutuality starts with changing our own mindset and the way of constructing and perceiving reality. It involves open discussions and appreciation of diverse opinions.

Tourism education is a medium through which mutual respect can be promoted. However, we believe that mutuality is a process that starts from self and therefore cannot be taught directly as a subject but rather facilitated through the whole variety of general selfawareness and conflict resolution courses which would need to be compulsory part of the whole tourism program (undergraduate and postgraduate). Another way of incorporating mutual respect 
into the tourism curricula is to ensure that students are exposed to diverse social and cultural values and behaviors, and to encourage positive attitude towards diversity.

Specific Learning Objectives are:

- The promotion of respect and the feeling of recognition

- Innovative thinking and learning methods.

- Closer cooperation with "real life" through joint development projects with the industry

- Students as active participants and decision makers, creating an atmosphere of mutual respect and support.

- The role of teachers should change from "fact tellers" to facilitators of a student's own development.

- A learning environment that is inclusive, safe and dynamic, where students are not afraid to take the initiative should be created.

- Self-awareness as a prerequisite to mutual respect should involve faculty, because teachers should understand their role as a positive change agents to promote mutuality.

- Continuous training is needed for all staff members to build an understanding of diverse cultural backgrounds and value systems.

- Teachers should be able to recognize their own values and be open to question and revisit these values.

- Mutual respect should be promoted between staff members as well as between teachers and students. 
Mutual respect is a process of self-development and thus is unique for every individual. Therefore, mutuality cannot be measured and assessed as a learning outcome in the curriculum. However, it is vital to incorporate mutuality elements and principles into study modules. Tourism curricula should be based on a variety of approaches, experiences and knowledge. It should incorporate courses related to professional and personal development, sociology, theology and cultural studies to facilitate students' understanding of drivers for change. Critical thinking skills should be emphasised in the curricula, and student's ability to initiate open dialogue, manage conflicts and reach mutually beneficial agreements should be rewarded. Programs promoting cooperation, inclusion and diversity should be included into tourism studies.

\subsection{Summary of Value-Based Principles}

The ideas presented above are meant to be used creatively by educators in their course materials. The specifics of how to incorporate them are left to the educator. Ways in which the TEFI Values can be incorporated into student learning and industry operations are discussed below.

\section{The Way Forward}

With the goal to fundamentally transform tourism education, TEFI is poised to progress in a number of ways. First, as we move forward it is critical that we engage all stakeholders. In particular, TEFI will work with leading university educators and industry professionals to define a new model of education for the tourism industry. In addition, we will invite students into the process to add their understanding to the redesign of education. Finally, we will also invite those in the upper levels of administration of university programs including deans, rectors, chancellors, 
provosts, etc. to gain their unique perspective and implementation possibilities.

TEFI fellows are already creating linkages with other organizations with similar visions, distributing a White Paper broadly to educators, industry, students and associations of educators worldwide. TEFI fellows are beginning to develop pilot programs in the university context to test the values framework and are planning two future TEFI Summits to bring their initiatives to its fruition. Each of these initiatives is discussed below.

1. Networking with other organizations:

- To influence accreditation and certification agencies such as UNWTO through the Tedqual certification, ACPHA and others

- To share outcomes with other agencies/groups working to change education such as Principles for Responsible Management Education (www.unprme.org), Academy of Hope

- To present the TEFI Guidelines at international, national and regional conferences such as ISTTE, BESTEN, CAUTHE - particularly those that are dealing with education and future leadership of the industry.

- To partner with industry associations such as World Travel and Tourism Council (WTTC).

- To partner with the International Academy for the Study of Tourism.

\section{Grants}

Numerous funding agencies have been identified for possible funding of the TEFI initiative. In particular, proposals will be written to obtain funds to support the development and 
evaluation of alternative educational strategies/programs/methods for integrating TEFI values into tourism curricula.

\section{Future TEFI Summits}

TEFI will hold a World Congress open to all tourism educators and industry leaders. It will be titled: TEFI World Congress: Activating Change in Tourism Education, and will be held at Temple University, Philadelphia, USA May 18-21, 2011.This World Congress will be an opportunity for all involved in the tourism education process from around the world (educators, administrators at all levels, industry, students and governments) to come together to learn about the initiative, to design strategy for its implementation on a global scale, and to identify new challenges and opportunities that tourism education is likely to face between now and 2030 .

\section{Pilot projects}

A few universities are beginning to structurally infuse their programs with TEFI values. For example, Modul University Vienna is using the values to create an oath that all students agree to upon graduation. Temple University in the USA is already using the values-based framework in its course design ensuring that each value set and its sub-values get coverage. James Cook University in Australia and University of Hawaii are both in the initial stages of implementing the values-based framework. Many individual members of TEFI are changing their individual courses to reflect the TEFI initiative.

Additionally, a TEFI Scholarship of Hope has been created at Modul University Vienna to encourage excellent students to continue their tourism studies. This scholarship is given to the winner of an essay competition in which the students must show how the values relate to stewardship and leadership in their lives. 


\section{TEFI Faculty Code of Ethics/Conduct and Student Oath}

The need for faculty to 'walk the talk' in addition to 'talking the talk' has been discussed numerous times at the various TEFI Summits. The role of faculty as mentors, role models and a source inspiration and knowledge for students is paramount in this initiative. The creation of a Code of Ethics will be developed to help guide faculty in playing this larger role in students' lives. In line with this code, examples of student codes that imbibe the TEFI values will be created.

\section{TEFI Values Assessment Inventory}

Tools to assess how students' values are being advanced within the TEFI framework and will be an important guideline to measure the success of the program. A TEFI Values Assessment Inventory to measure incoming and outgoing values of students, giving consideration to cultural differences will be developed.

In summary, the TEFI initiative is dynamic with many institutions and players involved. It is our hope that this collaborative effort succeed in shifting the focus of tourism education worldwide to provide more responsible graduates and better stewardship for destinations and their environmental and socio-cultural resources. We invite as many people as possible to walk this path with us and help to redefine tourism education and provide leadership for this vital field into the future.

TEFI has benefitted from the incredible participation of educators and industry members from around the world. This paper reflects their insight, creativity and concern for the future of 
tourism education. Working Groups have been led by various individuals who have played a key role in bringing the initiative to this point. Four meetings have been held to date that have been financially sponsored by universities from around the world with strong tourism programs: Temple University, University of Hawaii, and Virginia Tech University, USA, University of Queensland, La Trobe University and University of Victoria, Australia, Bocconi University, Italy, Modul University Vienna, University of Lugano, Switzerland, and University of Duesto, San Sebastian, Spain. They have also been sponsored by the International Academy for the Study of Tourism, the BEST Education Network and CICtourGUNE, San Sebastian, Spain. The Steering Committee that has guided TEFI includes Drs. Leo Jago, Janne Liburd, John Tribe, Karl Wöber, Pauline Sheldon, and Daniel Fesenmaier. We would also like to thank David Fennell for his thoughtful review of this paper and the suggestions he made, and the participants at the various summits who jointly contributed to this paper. 


\section{REFERENCES}

Althusser, L. (1984). Essays on Ideology. London: Verso.

Apple, M. (1990). Ideology and the Curriculum. London: Routledge and Kegan Paul.

Brotherton, B. (1999). Towards a definitive view of the nature of hospitality and hospitality management. International Journal of Contemporary Hospitality Management, 11(4), 165-173.

Bynum, T. W., \& Rogerson, S. (Eds.) (2004). Computer Ethics and Professional Responsibility. Blackwell.

Bynum, T., (2008). Computer and Information Ethics, in Zalta, E. N. (ed.), The Stanford Encyclopedia of Philosophy. Online at: <http://plato.stanford.edu/entries/ethicscomputer/>.

Cooper, T., Hofheinz, P., \& Purdy, M. (2007). Skills for the future. London: Accenture.

Enghagen, L. K. \& Hott, D. D. (1992), Students' perceptions of ethical issues in the hospitality and tourism industry. Hospitality Research Journal, 15(2), 41-50.

Enghagen, L. K. (1990). Teaching ethics in hospitality and tourism education. Hospitality Research Journal, 14(2), 467-474.

Fennell, D.A. (2000). Tourism and applied ethics. Tourism Recreation Research, 25 (1),59-69.

Floridi, L. (2008). Information Ethics, its Nature and Scope, invited chapter for Moral, in van den Hoven, J. and Weckert, J. (eds), Philosophy and Information Technology. Cambridge: Cambridge University Press, pp. 40-65.

Giddens, A. (2009). The politics of climate change. London: Polity Press.

Haga, W.J. (1976). "Managerial Professionalism and the Use of Organization Resources," American Joumal of Economics and Sociology, 35, 337-47.

Hall, S. S. (Ed.) (1992). Ethics in Hospitality Management: A Book of Readings. Educational Institute of American Hotel \& Motel Association.

Hoyle, E. \& John, P.D. (1995). Professional knowledge and professional practice. London: Cassell.

Hudson, S. \& Miller, G. (2006). Knowing the difference between right and wrong: The Response of Tourism Students to Ethical Dilemmas. Journal of Teaching in Travel and Tourism, 6 (2), 41-59.

Hudson, S.\& Miller, G. (2005) Ethical Orientation and Awareness of Tourism Students. Journal of Business Ethics, 62, 383-396.

Inglehart, R. (1990) Culture shift in advanced industrial society. Princeton, NJ: Princeton University Press.

Inglehart, R. (1997) Modernisation and postmodernisation. Princeton, NJ: Princeton University Press.

Jamal, T. \& Menzel, C. (2008). Good Actions in Tourism. In J. Tribe (ed.). Philosophical Issues in Tourism, pp. 227-243. Bristol, UK: Channel View Publications.

Jaszay, C. (2001). An Integrated Research Review of Ethics Articles in Hospitality Journals 1990 to 2000. Report. Isbell Endowment for Hospitality Ethics, Northern Arizona University. Accessed online (May 15, 2009) at http://www2.nau.edu/ clj5/Ethics/jaszay1.pdf

Jaszay, C. (2002). Teaching ethics in hospitality programs. Journal of Hospitality \& Tourism Education. 14(3), 58-63. 
Jaszay, C. (2006). Hospitality Ethics Curriculum. Prentice-Hall.

Kim, N. Y. \& Miller, G. (2008) Perceptions of the Ethical Climate in the Korean Tourism Industry. Journal of Business Ethics, 82(4), 941-954.

Kwansa, F. A. \& Farrar, A. L. (1992). A Conceptual Framework for Developing a Hospitality Educators' Code of Ethics. Journal of Hospitality \& Tourism Research, 15(3), 27-39.

Laudon, K. C. (1995). Ethical concepts and information technology. Communications of the ACM, 38(12), 33-39.

Lieberman-Nissen, K. (2005). Ethics in the Hospitality and Tourism Industry

Minnaert, L., Maitland, R. \& Miller, G. (2007) Defining social tourism: Linking the concept to its ethical foundations. Tourism Culture, 7(1), 7-17

Oddo, A. R. (1997). A framework for teaching business ethics. Journal of Business Ethics, 16(3), 293-297.

Reisinger, Y. (2009). International Tourism: Cultures and Behavior, Chapter 11 - Cultural Influences on Ethics, pp. 243-261. Elsevier-Butterworth-Heinemann.

Resnik, D. B. (2007). What is Ethics in Research \& Why is It Important? Online at: <http://www.niehs.nih.gov/research/resources/bioethics/whatis.cfm>.

Rikowski, R. (2006). Teaching ethical issues in Information Technology: how and when Information for Social Change, 23, 128-153. Online at: <http://libr.org/isc/issues/ISC23/B9a Ruth Rikowski.pdf>.

Sachs, J. (2003). Teacher professional standards: controlling or developing teaching, Teachers and teaching: theory and practice, 9 (2), 175-186.

Satris, S. (2002). The South Carolina State House and the Confederate Flag - Ethics Case Study (Heritage tourism). Teaching Business Ethics, 2(2), 71-76. (see also and the comments, online at: http://www.rit.edu/cla/ethics/seac/Vol2.2.html)

Shamoo, A. \& Resnik, D. (2003). Responsible Conduct of Research. Oxford University Press.

Shannon, J. R. \& Berl, R. L. (1997). Are we teaching ethics in marketing? A survey of students' attitudes and perception. Journal of Business Ethics, 16(10),1059-1075.

Sheldon, P., Fesenmaier, D. Wöber, K., Cooper, C., \& Antonioli, M. (2008). Tourism Education Futures - 2010-2030:Building the Capacity to Lead, Journal of Teaching in Tourism and Travel.

Smith, M. \& Duffy, R. (2003). The Ethics of Tourism Development. Routledge.

Stevens, B. (2001). Hospitality Ethics: Responses from Human Resource Directors and Students to Seven Ethical Scenarios. Journal of Business Ethics, 30(3), 233-242

Tribe, J. (2002). The philosophic practitioner. Annals of Tourism Research, 29, 338-357.

Tribe, J. (2002). Education for ethical tourism action. Journal of Sustainable Tourism, 10(4), 309-324.

Vallen, G. \& Casado, M. (2000). Ethical principles for the hospitality curriculum. Cornell Hotel and Restaurant Administrative Quarterly, 41(2), 44-51.

Velasquez, M. G. (1998). Business Ethics, Concepts and Cases. Prentice-Hall.

Vessuri, H. (2002). Ethical Challenges for the Social Sciences on the Threshold of the 21st Century. Current Sociology, 50(1), 135-150.

Wallis, C., and Steptoe, S. (2006) How to bring our Schools out of the 20th Century. Time, Sunday, 10th December.

Webster, A. (2001) Spiral of Values: The flow from survival values to global consciousness in New Zealand. Hawera, NZ: Alpha Publications.

Weckert, J. (Ed.). (2007). Computer Ethics. Ashgate. 
Williamson, J. (1997). The Washington consensus revisited. Economic and social development into the XXI century, 48-61.

Yaman, H. R. (2003). Skinner's Naturalism as a Paradigm for Teaching Business Ethics: A Discussion from Tourism. Teaching Business Ethics, 7(2), 107-122.

Yeung, S. \& Pine, R. (2003). Designing a hospitality ethics course content from the students' perspective. Journal of Teaching in Travel \& Tourism, 3(2), 19-33.

Yeung, S. (2004). Hospitality ethics curriculum: an industry perspective. International Journal of Contemporary Hospitality Management, 16(4), 253-262. 
Figure 1. The TEFI Values of Tourism Education

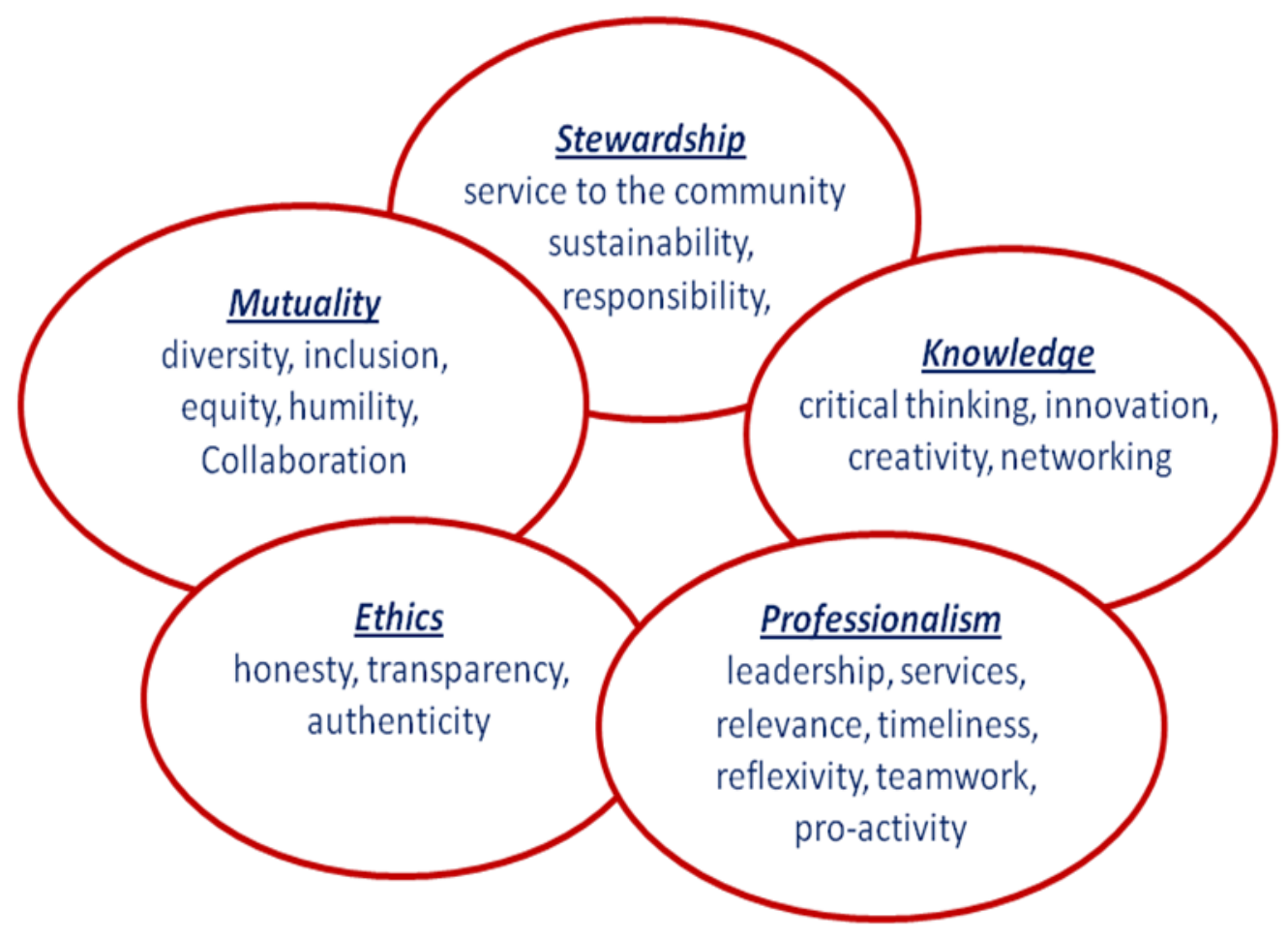

TEFI Values 